\title{
Daily Activity and Light Exposure Levels for Five Species of Lemurs at the Duke Lemur Center
}

\author{
Mark S. Rea, ${ }^{1}$ Mariana G. Figueiro, ${ }^{1}$ Geoffrey E. Jones, ${ }^{1}$ \\ and Kenneth E. Glander ${ }^{2 *}$ \\ ${ }^{1}$ Lighting Research Center, Rensselaer Polytechnic Institute, Troy, NY 12180 \\ ${ }^{2}$ Department of Evolutionary Anthropology, Duke University, Durham, \\ NC 27708-0383
}

\section{KEY WORDS photic niche; Daysimeter-D; diurnal; cathemeral; nocturnal}

\begin{abstract}
Light is the primary synchronizer of all biological rhythms, yet little is known about the role of the 24-hour luminous environment on nonhuman primate circadian patterns, making it difficult to understand the photic niche of the ancestral primate. Here we present the first data on proximate light-dark exposure and activity-rest patterns in free-ranging nonhuman primates. Four individuals each of five species of lemurs at the Duke Lemur Center (Eulemur mongoz, Lemur catta, Propithecus coquereli, Varecia rubra, and Varecia variegata variegata) were fitted with a Daysimeter-D pendant that contained light and accelerometer sensors. Our results reveal common as well as species-specific light exposure and behavior patterns.
\end{abstract}

Primates obviously need light to see, but light falling on the retina is also the most important synchronizer (zeitgeber) of circadian rhythms to their local position on Earth (Refinetti, 2006). Like light for vision, the synchronizing light for the circadian system must be processed by the retinal photoreceptors. There are five known types of photoreceptors in the human retina, rods, three cone types: long-wavelength sensitive, middle-wavelength sensitive, and short-wavelength sensitive (L-, M-, and S-cones, respectively), and intrinsically photosensitive retinal ganglion cells (ipRGCs). All five types combine to form the spectral sensitivity of the human circadian system (Rea et al., 2005). Diurnal lemur (e.g., Lemur catta) retinas are believed to contain rods and just two cone types, an S-cone and a middle- to long-wavelength sensitive cone, the L-cone (Jacobs, 2009). Rod and S-cone peak spectral sensitivities in lemurs are very close to the comparable photoreceptors in humans, whereas the peak spectral sensitivity of the lemur L-cone is between those of the human L- and Mcone spectral sensitivities (Jacobs and Deegan, 1993; Jacobs, 2009). Although never documented in lemurs, all mammalian retinas are believed to contain ipRGCs, which are essential to circadian phototransduction (Bellingham and Foster, 2002; Bellingham et al., 2006; Pierson and Foster, 2006). Thus, diurnal lemurs and humans appear to have similar retinal photoreceptors, and presumably subsequent neural mechanisms, underlying circadian phototransduction.

Light, or more accurately the light-dark cycle, as a synchronizer of circadian rhythms may be a key element shaping primate evolution as evidenced by the ongoing debate about whether the photic niche of the ancestral
As expected, all five species were more active between sunrise and sunset. All five species demonstrated an anticipatory increase in their pre-sunrise activity that peaked at sunrise with all but V. rubra showing a reduction within an hour. All five species reduced activity during mid-day. Four of the five stayed active after sunset, but $P$. coquereli began reducing their activity about 2 hours before sunset. Other subtle differences in the recorded light exposure and activity patterns suggest species-specific photic niches and behaviors. The eventual application of the Daysimeter-D in the wild may help to better understand the adaptive evolution of ancestral primates. Am J Phys Anthropol 153:68-77, 2014. () 2013 Wiley Periodicals, Inc.

primate was diurnal, nocturnal, or cathemeral ${ }^{\dagger}$ (Martin, 1994; Tan et al., 2005; Perry et al., 2007). The traditional view is that the ancestor of living primates was nocturnal and that many modern prosimians retained nocturnality (Martin, 1994; Heesy and Ross, 2001; Martin and Ross, 2005; Bearder et al., 2006; Ross and Kirk, 2007). However, Tan et al. (2005) proposed that the ancestral primate was either diurnal or cathemeral with at least seven shifts to nocturnality in modern prosimians. Both Kappeler and Erkert (2003) and van Schaik and Kappeler (1996) suggested that cathemerality could be a transitory stage from the nocturnal to a diurnal photic niche. This debate is based on observations of

\footnotetext{
The activity of an organism can be regarded as cathemeral when it is distributed approximately evenly throughout the $24 \mathrm{~h}$ of the daily cycle, or when significant amounts of activity, particularly feeding and/or travelling, occur within both the light and dark portions of that cycle (Tattersall, 1987, p. 201).
}

Grant sponsor: Margo Marsh Biodiversity Foundation and Lighting Research Center.

*Correspondence to: Kenneth E. Glander, Department of Evolutionary Anthropology, Duke University, 130 Science Drive, Room 108, Box 90383, Durham, NC 27708, USA. E-mail: glander@duke.edu

Received 11 October 2013; accepted 12 October 2013

DOI: 10.1002/ajpa.22409

Published online 6 November 2013 in Wiley Online Library

(wileyonlinelibrary.com). 

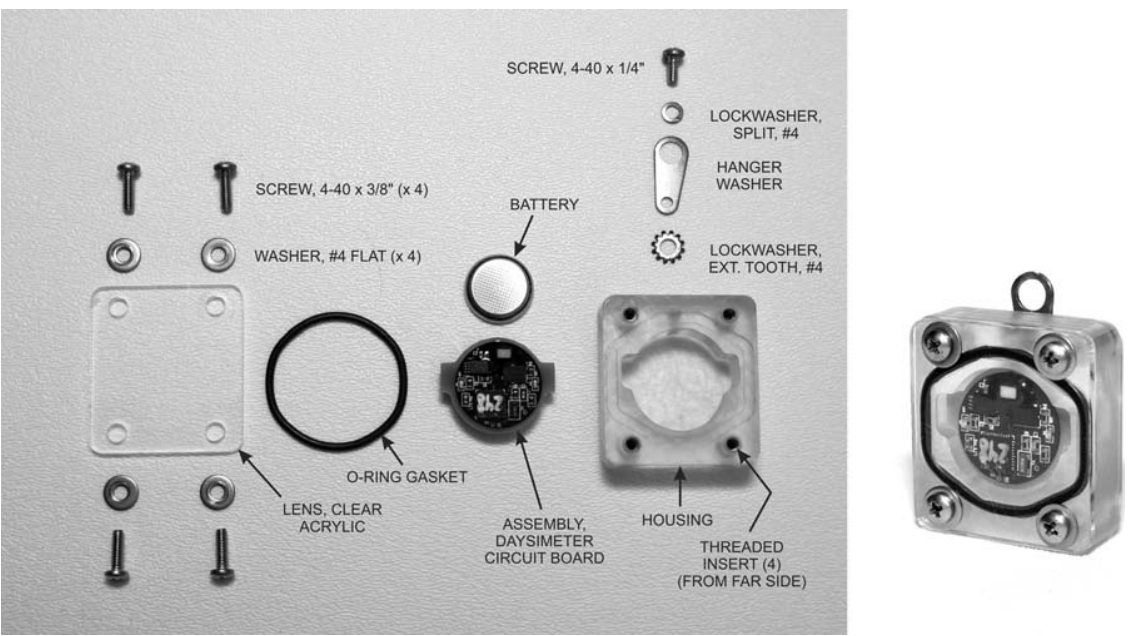

Fig. 1. The Daysimeter-D records light and activity over several weeks. For field deployment, it is housed in an acrylic case. The total weight of the Daysimeter-D and its case is $25.25 \mathrm{~g}$.

nychthemeral activity and opsin genes in modern lemurs (proxy for the extinct primate ancestors) with the conclusions used as indicators of shifting evolutionary position, for example, from nocturnal to diurnal or diurnal to nocturnal activity. This transition is considered to be a critical step in the evolutionary path of primates (Heesy and Ross, 2001; Martin et al., 2003), but relatively little is known about the relationship between 24-hour lightdark exposure patterns and rest-activity patterns in nonhuman primates.

There are complicating issues affecting this debate. First, published data demonstrating that some lemur species switch between photic niches or occupy different photic niches in the same and in different habitats. For example, Tattersall $(1976,1978)$ reported that Eulemur mongoz on the Comoro islands of Mohéli and Anjouan to be seasonally nocturnal both on Mohéli and in the lowlands of Anjouan but diurnal in the highlands of Anjouan. Similarly, Lemur catta are generally considered to be diurnal (Sauther et al., 1999) but Donati et al. (2013) and Lafleur (2012) reported them to be cathemeral. Explanations range from predator presence or absence, to energy expenditure, thermoregulation, and competition (Curtis and Rasmussen, 2002; Kappeler and Erkert, 2003; Colquhoun, 2006; Donati et al., 2007, 2009, 2010). All of these findings are based on activity collected by direct observation, activity loggers, and camera traps, but light exposure patterns as they may affect their biological rhythms in the animal's natural habitat were not measured. Second, many early studies used clock time rather than the solar markers of sunrise and sunset resulting in erroneous assumptions about behavior timing (Nouvellet et al., 2012). However, recent studies of Eulemur fulvus rufus by Erkert and Cramer (2006) and Kappeler and Erkert (2003), Propithecus v. verreauxi by Erkert and Kappeler (2004), Aotus by Erkert et al. (2012), Fernández-Duque and Erkert (2006), Fernández-Duque et al. (2010) and L. catta by Donati et al. (2013) eliminated these errors by using astronomical time in their analyses.

Here we present for the first time, results from the application of a small, collar-mounted technology developed by the Lighting Research Center (LRC), the Daysimeter-D (Fig. 1), used to measure proximate light- dark exposure patterns and associated activity-rest patterns over several days in five species of free-ranging lemurs. The physical characteristics of the Daysimeter-D and its calibration have been previously documented (Figueiro et al., 2012). Briefly, light sensing by the Daysimeter-D is performed with an integrated circuit sensor array that includes optical filters for four measurement channels: red (R), green $(\mathrm{G})$, blue $(B)$, and infrared (IR). The R, G, B, and IR photoelements have peak spectral responses at $615 \mathrm{~nm}, 530 \mathrm{~nm}, 460 \mathrm{~nm}$, and $855 \mathrm{~nm}$, respectively. The Daysimeter-D is calibrated in terms of orthodox photopic illuminance (lux) and of circadian illuminance $\left(\mathrm{CL}_{\mathrm{A}}\right)$. $\mathrm{CL}_{\mathrm{A}}$ calibration is based upon the spectral sensitivity of the human circadian system. From the recorded $\mathrm{CL}_{\mathrm{A}}$ values, it is then possible to determine the circadian stimulus (CS) magnitude, which represents the input-output operating characteristics of the human circadian system from threshold to saturation (Rea et al., 2005, 2010). The Daysimeter-D also has three, orthogonally oriented, solid-state accelerometers that are calibrated in terms of gravitational forces on the device, which allows for continuous measures of rest/activity patterns. An activity index (AI) is calculated from the three accelerometer channels using the following formula: $\mathrm{AI}=k \sqrt{\left(\mathrm{SS}_{x}+\mathrm{SS}_{y}+\mathrm{SS}_{z}\right) / n}$, where $\mathrm{SS}_{x}, \mathrm{SS}_{y}$, and $\mathrm{SS}_{z}$ are the sum of the squared deviations from the mean of each channel over the logging interval, $n$ is the number of samples in a given logging interval, and $k$ is a calibration factor equal to $0.0039 \mathrm{~g}$ per count. Logging intervals for acquiring light and activity data are set by the experimenter; for this study, the logging interval was set at 3 minutes.

The recorded light-dark and activity-rest patterns make it possible to quantitatively assess the degree of circadian entrainment exhibited by the person or animal wearing the device using a technique known as phasor analysis. Phasor analysis as applied to measure circadian entrainment has been described elsewhere (Rea et al., 2008; Miller et al., 2010) but, briefly, the relationship between the 24-hour light-dark exposure (CS) pattern, the stimulus, and the rest-activity (AI) pattern, the response, can be quantified in terms of angle and magnitude. The phasor magnitude represents the strength of association between the light-dark pattern 
TABLE 1. Lemur species, number of subjects, subject genders, environmental conditions, and study dates

\begin{tabular}{lccc}
\hline Species & $N$ & M:F & Environment \\
\hline Mongoose lemurs & 4 & $2: 2$ & Indoor and outdoor \\
Ring-tailed lemurs & 2 & $1: 1$ & Indoor and outdoor \\
Ring-tailed lemurs & 2 & $1: 1$ & Indoor \\
Coquerel's sifakas & 4 & $2: 2$ & Indoor and outdoor \\
Red ruffed lemurs & 4 & $2: 2$ & Indoor and outdoor \\
Variegated black-and- & 4 & $2: 2$ & Indoor and outdoor \\
\multicolumn{1}{c}{ white ruffed lemurs } & & & September 21-26 \\
\hline
\end{tabular}

and the associated activity-rest pattern; greater phasor magnitudes indicate greater levels of circadian entrainment. The phasor angle is a measure of the phase relationship between the 24-hour light-dark exposure pattern and the 24-hour activity-rest pattern.

Using the Daysimeter-D device and phasor analysis, it became possible, for the first time, to measure daily light-dark and activity-rest patterns and to quantitatively assess light-dark and activity-rest patterns to determine circadian entrainment in five lemur species presently housed at the Duke Lemur Center (DLC). This information enables unique comparisons among lemur species and to humans that may provide evolutionary insights into these primates.

\section{METHODS}

\section{Study animals}

Four individuals each of Eulemur mongoz, Lemur catta, Propithecus coquereli, Varecia rubra, and Varecia variegata variegata served as subjects in the study. All subjects were adults (Table 1) and, with the exception of two Lemur catta subjects, allowed access to an adjacent Natural Habitat Enclosure (NHE) and to interact normally with their own social group during the study. This project was approved by the Duke University Institutional Animal Care and Use Committee (protocol A14910-06) and by the DLC Research Committee.

Eulemur mongoz or mongoose lemurs live in family units consisting of one adult female, one adult male, and one to four offspring (Curtis and Zaramody, 1999). Their wild diet consists of fruit, flowers, nectar, and leaves (Curtis et al., 1999), and their activity pattern is classified as cathemeral (Curtis et al., 1999; Curtis and Rasmussen, 2006).

Lemur catta or ring-tailed lemurs live in multi-male/ multi-female social groups ranging from 10 to 20 (Sauther et al., 1999). They spend more time on the ground than other lemurs (Sussman, 1974), and their diet is primarily fruit, leaves, and flowers (Simmen et al., 2006). Females are dominant to males (Kappeler, 1990; Sauther, 1993).

Propithecus coquereli (formerly called $P$. verreauxi coquereli) or Coquerel's sifaka live in both one male/one female and multi-male/multi-female groups ranging in size from 5 to 8 (Richard, 1974, 1985). Their primary diet is new and mature leaves, flowers, fruit, and deadwood, and they are reported to be diurnal (Richard, 1974, 1978). Females are dominant to males (Richard, 1974).

Varecia rubra or red ruffed lemurs live in fission-fusion groups that are multi-male multi-female and range from 5 to 30 individuals (Vasey, 2000). They are the most frugivorous lemur with a diet that may be up to $88 \%$ fruit, with the rest being flowers and new leaves (Vasey, 2000). They are diurnal and keep their young in nests (Vasey, 2005)

Varecia variegata variegata or variegated black-andwhite ruffed lemurs are similar to red ruffed lemurs in social structure, group size, diet, and nest building (Morland, 1991; White et al., 1992; Britt, 2000). They are reported to be both diurnal and cathemeral (Pereira et al., 1988; Morland, 1991).

\section{Animal housing}

All subjects were housed at the DLC (N $35^{\circ} 59^{\prime} 35^{\prime \prime} \mathrm{W}$ $\left.78^{\circ} 57^{\prime} 38^{\prime \prime}\right)$. Housing consisted of indoor rooms connected to outdoor chain-link runs that allowed restricted access to an adjacent NHE. All indoor rooms were temperature controlled and equipped with $28-\mathrm{W}$ T5 Linear Fluorescent $4100 \mathrm{~K}$ lamps that are controlled by automatic timers set to astronomical time. Astronomical sunset and sunrise were obtained from the U.S. Naval Observatory (http://aa.usno. navy.mil/data). Indoor, horizontal illuminance levels measured at a height of approximately $1 \mathrm{~m}$ ranged from 95 to 179 lux (Dr. Meter Digital Light Meter Lx1330B). The DLC is located in a rural, wooded area that, with the exception of the parking lot, is not illuminated at night. Only the variegated black-and-white ruffed subjects had visual access to the DLC parking lot, which provides approximately 5 lux on the parking surface from high-pressure sodium (HPS) light sources near the lemur shelter. One ring-tailed lemur pair was limited to indoor rooms while the other ring-tailed lemur pair and all other individuals within their groups were free to occupy indoor rooms, outside chain-link cages, or the NHE.

\section{Placement of the Daysimeter-D}

Since photic input to the circadian system must come through the eyes, the best location for quantifying circadian light exposure in any species would be to place a Daysimeter-D near the cornea. Figueiro et al. (2012) showed that, in contrast to the wrist, Daysimeter-Ds

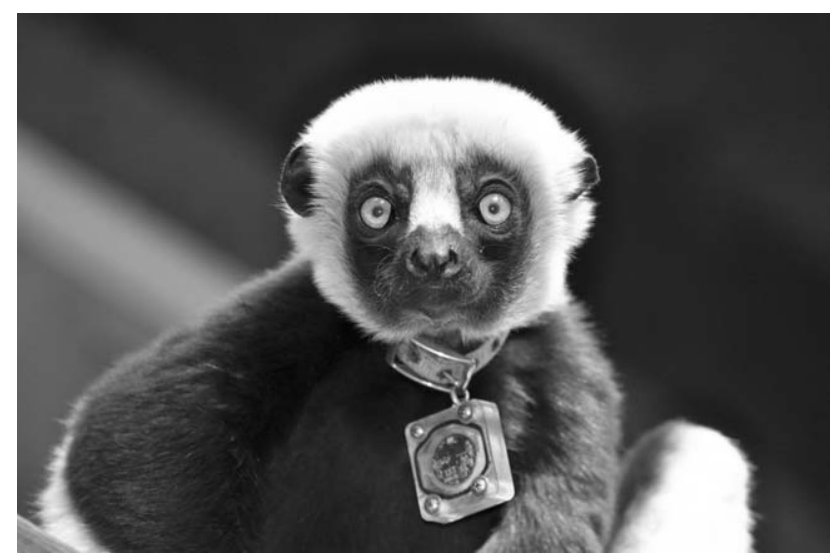

Fig. 2. A DLC Coquerel's sifaka wearing the 25-g Daysimeter-D. 

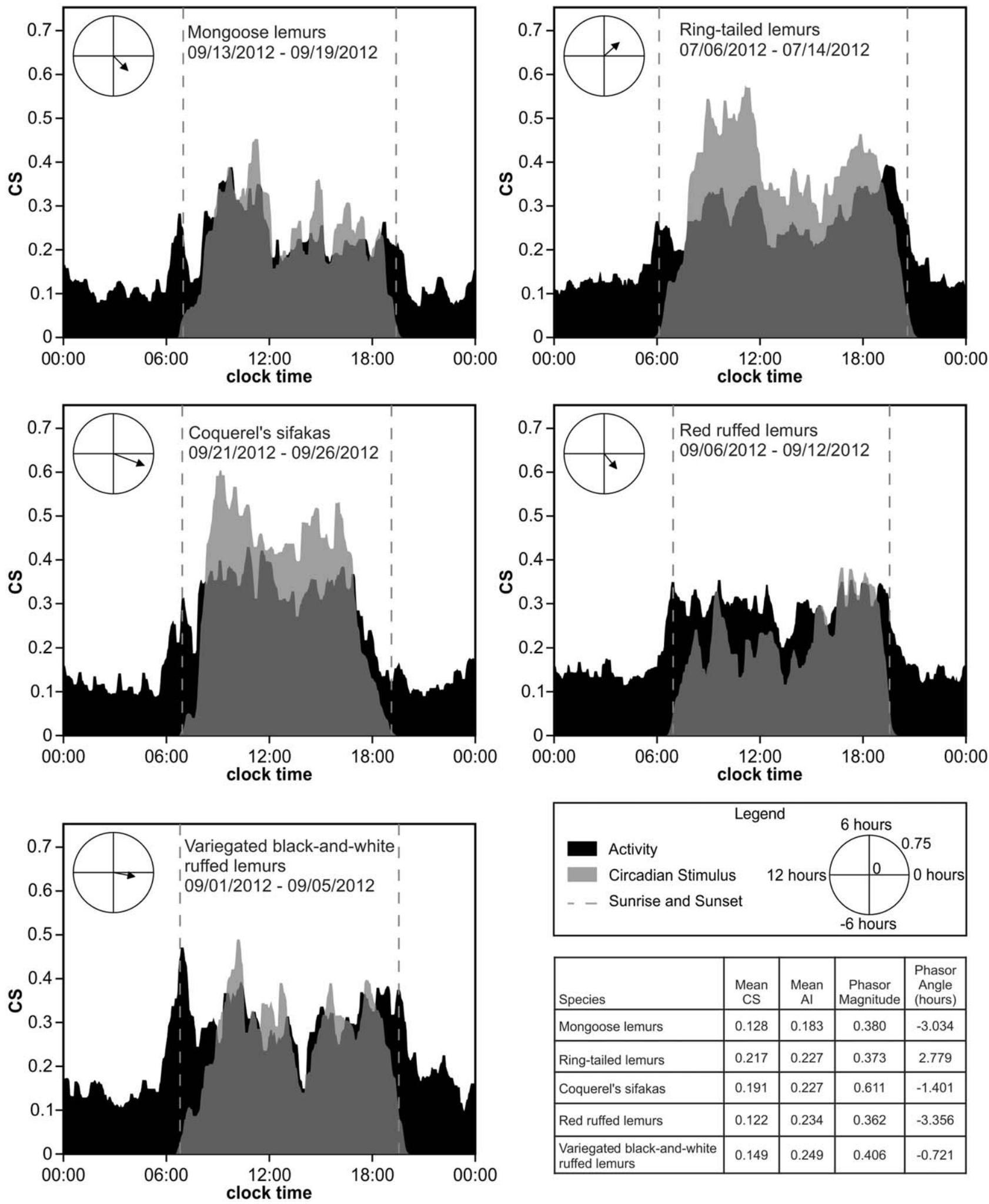

\begin{tabular}{|l|c|c|c|c|}
\hline Species & $\begin{array}{c}\text { Mean } \\
\text { CS }\end{array}$ & $\begin{array}{c}\text { Mean } \\
\text { Al }\end{array}$ & $\begin{array}{c}\text { Phasor } \\
\text { Magnitude }\end{array}$ & $\begin{array}{c}\text { Phasor } \\
\text { Angle } \\
\text { (hours) }\end{array}$ \\
\hline Mongoose lemurs & 0.128 & 0.183 & 0.380 & -3.034 \\
\hline Ring-tailed lemurs & 0.217 & 0.227 & 0.373 & 2.779 \\
\hline Coquerel's sifakas & 0.191 & 0.227 & 0.611 & -1.401 \\
\hline Red ruffed lemurs & 0.122 & 0.234 & 0.362 & -3.356 \\
\hline $\begin{array}{l}\text { Variegated black-and-white } \\
\text { ruffed lemurs }\end{array}$ & 0.149 & 0.249 & 0.406 & -0.721 \\
\hline
\end{tabular}

Fig. 3. Light and activity patterns for five species of lemurs as measured with a collar-mounted Daysimeter-D. Phasor diagrams are included in the upper left corner of each panel showing the magnitude and angle of behavioral circadian entrainment exhibited by each species. Traces represent the daily averages of light and activity over 1 week for four animals of each species. All lemur activity and light data were smoothed using a moving median filter where the filtering window is 21 minutes in length. Thus, the traces represent the average light and activity of four lemurs over a 21-minute duration. 
TABLE 2. Lemur species, mean activity per hour, mean daytime activity per hour, mean night-time activity per hour, and day/night $(D / N)$ activity ratio

\begin{tabular}{|c|c|c|c|c|}
\hline Species & $\begin{array}{c}\text { Mean } \\
(\mathrm{AI} / \text { hour }) \times 10^{-3}\end{array}$ & $\begin{array}{l}\text { Mean daytime } \\
(\mathrm{AI} / \text { hour }) \times 10^{-3}\end{array}$ & $\begin{array}{l}\text { Mean night-time } \\
(\mathrm{AI} / \text { hour }) \times 10^{-3}\end{array}$ & $\begin{array}{c}\text { Day/night } \\
\text { AI ratio }\end{array}$ \\
\hline Mongoose lemurs & 9.2 & 12.0 & 6.2 & 1.96 \\
\hline $\begin{array}{l}\text { Ring-tailed lemurs } \\
\text { (excluding indoor) }\end{array}$ & 11.3 & 14.2 & 7.1 & 2.00 \\
\hline Coquerel's sifaka & 11.4 & 15.9 & 6.8 & 2.41 \\
\hline Red ruffed lemurs & 11.7 & 15.0 & 7.9 & 1.90 \\
\hline $\begin{array}{l}\text { Variegated black-and-white } \\
\text { ruffed lemurs }\end{array}$ & 12.5 & 15.5 & 8.9 & 1.72 \\
\hline
\end{tabular}

worn as a pendant provided data comparable to those obtained near the cornea. In this study, the lemurs wore the Daysimeter-D devices as pendants (Fig. 2).

\section{Procedures}

Individuals were netted in their indoor rooms and hand-held while the Daysimeter-D was attached to their collars or a new collar with Daysimeter-D was placed around their neck. This took approximately 5 minutes after which the individuals were released. In a majority of cases, the $25 \mathrm{~g}$ Daysimeter-D was attached to the collar that individuals were already wearing and there was no period of adjustment. Within 2 hours, all lemurs had acclimated to the collar-mounted Daysimeter-D.

\section{Data collection}

All four individuals of each species wore the Daysimeter-D for the same number of days, but the test days for any species did not overlap (Table 1). The test periods were chosen for convenience.

\section{Data analysis}

$\mathrm{CS}$ and AI data gathered by the collar-mounted Daysimeter-D were used in this study. Graphical presentations of the CS and AI patterns across the 24-hour day were generated for visual comparisons among the five lemur species and to different human populations. A moving median filter, with a window size of 21 minutes, was applied to both the CS and AI data from the lemurs to minimize sudden transients in light exposures and activity counts. This smoothing operation facilitates visual comparisons to the previously published human data, which were based upon much larger sample sizes. The selection of the filter size was visually determined to minimize loss of detail. Average CS and AI levels were determined for each lemur and these values were then averaged with other subjects of the species.

Relative AI during daytime was calculated from AI values obtained between sunrise and sunset divided by the total AI values recorded for the subject; this calculation also determines the relative amount of AI during the night-time. The average AI during the daytime and during the night-time were then determined for each species. The 24-hour phasor magnitudes and angles were calculated from the weeklong CS and AI patterns.

\section{RESULTS}

\section{Light-dark and rest-activity patterns}

Figure 3 shows average light (CS, gray) and activity (AI, black) over 24 hours for each of the five species of lemurs that were monitored at DLC; sunrise and sunset times are demarcated in each figure panel for that species. CS light exposures as measured by the collarmounted Daysimeter-D were restricted to daytime in all five species. The highest average CS was measured with ring-tailed lemurs and the lowest with red ruffed lemurs. All five species were more active between sunrise and sunset than at night as shown by the day/night $(\mathrm{D} / \mathrm{N})$ activity ratios (Table 2). All five species exhibited increased activity in anticipation of sunrise with a peak at sunrise; while four of the five had a reduction in activity within an hour of dawn (Fig. 3), red ruffed lemurs maintained a consistent activity level after sunrise until exhibiting a quiescent period during the middle of the day (Fig 3). In fact, all five species exhibited a similar reduction in activity in association with a reduction in light exposure during the middle of the day. Three of the five species (red ruffed, variegated black-and-white ruffed, and mongoose lemurs) spent this mid-day siesta period under lower light levels than experienced during the morning. This was also true of Coquerel's sifaka and ring-tailed lemurs that, based upon the high levels of CS, likely remained outdoors throughout most of the day (Fig. 3). Four of the five species exhibited a rise in activity toward sunset. In contrast, Coquerel's sifaka lemurs dramatically reduced their activity 2 hours before sunset (Fig. 3); this species also exhibited the highest day/night activity ratio (Table 2). It is interesting to note that average activity levels were similar across the five species with the possible exception of mongoose lemurs that exhibited less total activity than the other four species. Among the five species studied the mongoose lemurs were also exposed to relatively low levels of light during the day except during the mid-morning period.

Figure 4 shows the average light exposures (CS, gray) and activity (AI, black) for each individual ring-tailed lemur under two different housing conditions. Light exposures were much lower for the two animals with restricted access to the NHE than for the two animals that had unrestricted access to the outside area. However, the two indoor individuals had activity levels similar to the two individuals that had access to outdoors, and sex did not have any significant differential effect on their activity patterns (Table 3).

\section{Phasor analyses}

Phasor analysis is, again, used to quantify circadian entrainment by comparing the daily light-dark exposure pattern with the daily activity-rest pattern. Figures 3 and 4 provide phasor magnitudes and phasor angles for the five species of lemurs. In comparison to different human populations previously studied (Fig. 5), the average phasor magnitudes exhibited by every lemur species suggest that the animals are entrained to the natural, 

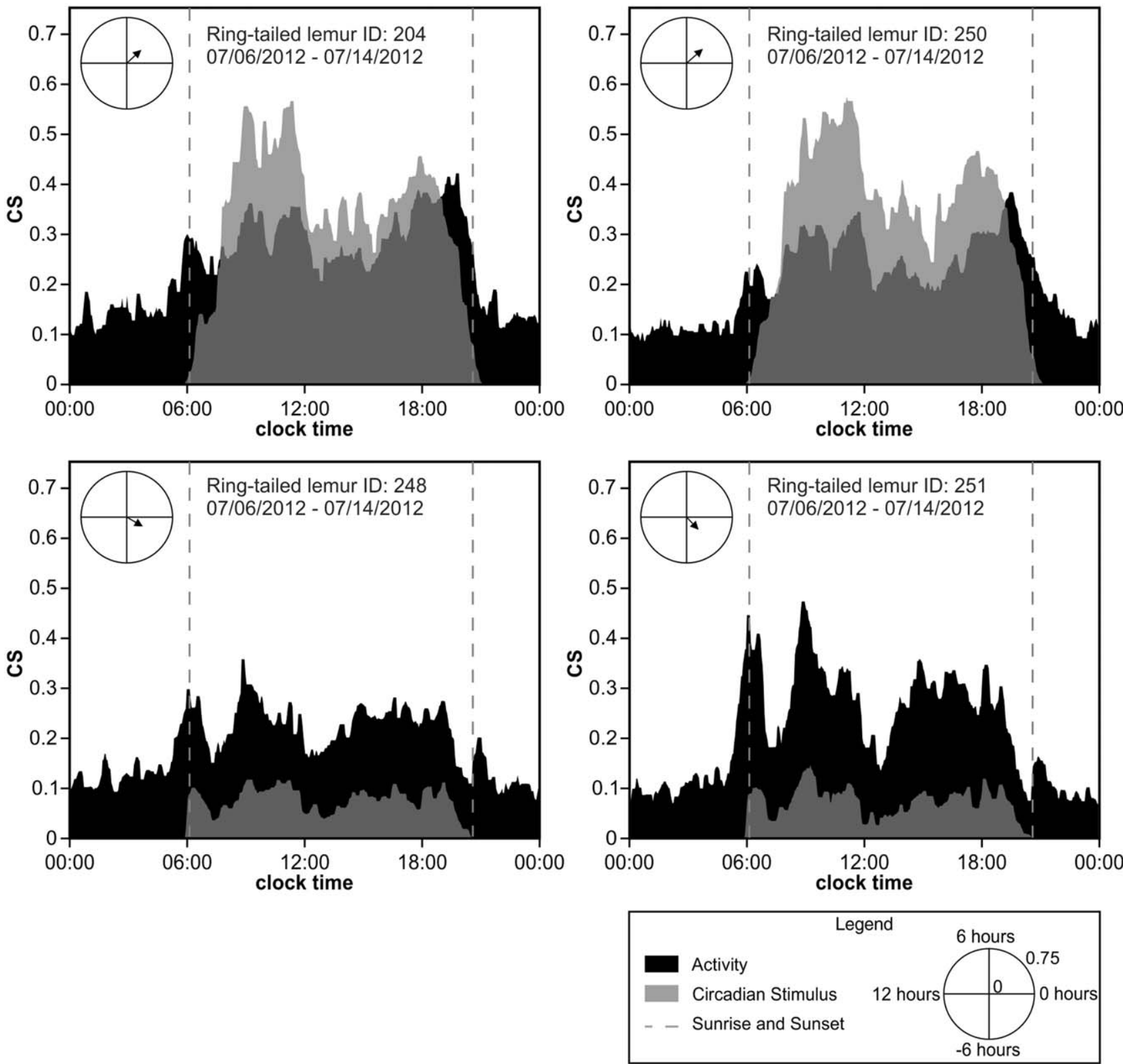

\begin{tabular}{|c|c|c|c|c|}
\hline \multicolumn{5}{|c|}{ Ring-tailed lemurs } \\
\hline ID \& Sex & Mean CS & Mean Al & $\begin{array}{c}\text { Phasor } \\
\text { Magnitude } \\
\end{array}$ & $\begin{array}{c}\text { Phasor } \\
\text { Angle } \\
\text { (hours) }\end{array}$ \\
\hline 204 운 & 0.214 & 0.244 & 0.316 & 2.820 \\
\hline 250 ठే & 0.219 & 0.210 & 0.347 & 2.739 \\
\hline $248 \sigma^{\pi}$ & 0.048 & 0.193 & 0.299 & -2.006 \\
\hline 251 우 & 0.046 & 0.218 & 0.277 & -3.085 \\
\hline
\end{tabular}

Fig. 4. Light and activity patterns for four ring-tailed lemurs, two with unrestricted access to the outdoors (upper two panels) and two restricted to the indoors (lower two panels) as measured with a collar-mounted Daysimeter-D. Phasor diagrams are included in the upper left corner of each panel showing the magnitude and angle of behavioral circadian entrainment exhibited by each ring-tailed lemur. Traces represent the daily averages of light and activity over 1 week for each of the four animals.

24-hour light-dark exposure pattern. However, only ring-tailed lemurs with access to the bright outdoor NHE exhibit positive phasor angles indicating that their daily activity-rest pattern is slightly delayed with respect to the light-dark pattern. In other words, for these entrained animals, the distribution of daily activity is shifted toward the late light exposure period (i.e., afternoon). In contrast, the other four species of lemurs exhibit negative phasor angles indicating that their daily activity-rest pattern is advanced relative to their light- 
TABLE 3. Ring-tailed lemurs, identification number, sex, environment, mean activity per hour, daytime activity per hour, night-time activity per hour, and day/night $(D / N)$ activity ratio

\begin{tabular}{|c|c|c|c|c|c|}
\hline \multicolumn{6}{|c|}{ Ring-tailed lemurs } \\
\hline ID and sex & Environment & $\begin{array}{l}\text { Mean } \\
(\mathrm{AI} / \text { hour }) \times 10^{-3}\end{array}$ & $\begin{array}{l}\text { Mean daytime } \\
(\mathrm{AI} / \text { hour }) \times 10^{-3}\end{array}$ & $\begin{array}{l}\text { Mean night-time } \\
(\mathrm{AI} / \text { hour }) \times 10^{-3}\end{array}$ & $\begin{array}{l}\text { Day/night } \\
\text { AI ratio }\end{array}$ \\
\hline $204 \mathrm{~F}$ & Indoor and outdoor & 12.2 & 15.2 & 7.7 & 1.96 \\
\hline $250 \mathrm{M}$ & Indoor and outdoor & 10.5 & 13.1 & 6.5 & 2.03 \\
\hline $248 \mathrm{M}$ & Indoor & 9.6 & 11.5 & 6.8 & 1.68 \\
\hline $251 \mathrm{~F}$ & Indoor & 10.9 & 13.8 & 6.4 & 2.16 \\
\hline
\end{tabular}

dark pattern; that is, the distribution of daily activity is shifted toward early light exposures (i.e., morning). On the other hand, for the restricted pair of ring-tailed lemurs, their daily activity-rest pattern is advanced with respect to the light-dark exposure pattern like that shown by the other four species. However, the phasor magnitudes of the two restricted animals are lower than those associated with the other four species that showed negative phasor angles.

\section{DISCUSSION}

This study is the first to systematically measure circadian entrainment in five different species of lemurs based upon their daily light-dark and activity-rest pattern data collected using a calibrated measuring device, the collar-mounted Daysimeter-D. A technique known as phasor analysis used those data to provide quantitative assessments of circadian entrainment in these species. Based upon phasor analysis, all five species can be considered well entrained to a diurnal niche, but distinct variations in the daily light-dark and activity-rest patters were seen among species and within one species (ring-tailed lemurs). The unique data and the associated phasor analysis offered in this study may provide methods for gaining additional insight into the evolutionary paths of primates.

Generally, all wild Eulemur species are considered to be cathemeral (Sussman and Tattersall, 1976; Donati et al., 2001; Curtis and Rasmussen, 2002, 2006; Donati and Borgognini-Tarli, 2006), but the literature is incomplete and often contradictory in this regard for other lemur species. In an attempt to measure diurnal versus cathemeral activity in five species, we examined the ratio of daytime and night-time activity levels $(\mathrm{D} / \mathrm{N})$. Low values of $\mathrm{D} / \mathrm{N}$ indicate activity is more evenly distributed throughout the 24-hour circadian cycle. Therefore, these lemurs would more likely exhibit cathemeral behavior than those lemurs with high $\mathrm{D} / \mathrm{N}$ values. The highest $\mathrm{D} / \mathrm{N}$ values of the lemur studied here were associated with ring-tailed and the Coquerel's sifaka lemurs and the lowest associated with red ruffed and variegated black-and-white ruffed lemurs. D/N values, if indeed they are indicators of cathemerality, are somewhat at odds with reports in the literature.

Variegated black-and-white ruffed lemurs have been assumed to exhibit limited cathemeral behavior because night-time activity has been reported in the literature only once in the wild (Moreland, 1991). This species had the lowest $\mathrm{D} / \mathrm{N}$ value (1.72), suggesting that night-time activity was actually more prominent for this species than for the others in this study. As noted by Donati et al. (2013), nocturnal activity is more likely to occur when a source of illumination, such as the moon, is available at night. The black-and-white ruffed lemurs were housed adjacent to the DLC parking lot that was illuminated at night with HPS sources. Thus, the relatively low $\mathrm{D} / \mathrm{N}$ values associated with this species may have been the result of the electric lighting in the parking lot that enabled nocturnal activity. Nevertheless, this species still maintained a high level of circadian entrainment as indicated by the relatively high phasor magnitude.

Cathemeral activity for ring-tailed lemurs has been reported in the literature (Traina, 2001; Lafleur, 2012; Donati et al., 2013), but in contrast to the black-andwhite ruffed lemurs, this species showed one of the highest $\mathrm{D} / \mathrm{N}$ values (2.00) in this study suggesting there was only limited activity at night. A more systematic assessment of cathemerality is possible with this species in this study because one pair of lemurs was housed inside the DLC facility throughout the measurement period while the other pair had unlimited access to the NHE. No electric lighting was available inside the facility at night and only small windows provided visual access to the outdoors, yet both pairs had nearly identical average $\mathrm{D} / \mathrm{N}$ ratios (2.00 versus 1.92$)$. Since ambient light was probably unavailable for deliberate activities at night to the pair housed inside the facility, and since the unrestricted animals had nearly the same $\mathrm{D} / \mathrm{N}$ ratio values, it seems unlikely that this species consistently exhibited cathemeral activity during the measurement period. Donati et al. (2013) observed that longer days (i.e., in summer) were associated with more activity during the day by ring-tailed lemurs in the wild but that night length was not related to nocturnal activity. The measurement period for the ring-tailed lemurs studied here occurred in July, near the longest day of the year in Durham, NC. Perhaps, these ring-tailed lemurs had limited activity at night because they were very active during the long summer day. Without seasonal data, it is difficult to consider this speculation as more than a hypothesis for future studies. Nocturnal activity has been associated with moonlight (Lafleur, 2012; Donati et al., 2013). In fact, the moon was present during the measurement period (http://aa.usno. navy.mil/data) for these ring-tailed lemurs, offering the possibility that the unrestricted lemurs would be active at night. Again, the similar $\mathrm{D} / \mathrm{N}$ values associated with the restricted and unrestricted ring-tailed lemurs do not support the inference that those with access to the NHE were more active at night than those confined to nighttime darkness. Both pairs of ring-tailed lemurs were, based upon their phasor magnitudes, well entrained to the natural, 24-hour light-dark cycle. In any event, systematic studies aimed at resolving these ambiguities can now be performed because light exposure and activity patterns can be gathered continuously throughout the 24-hour lightdark cycle using the collar-mounted Daysimeter-D. 

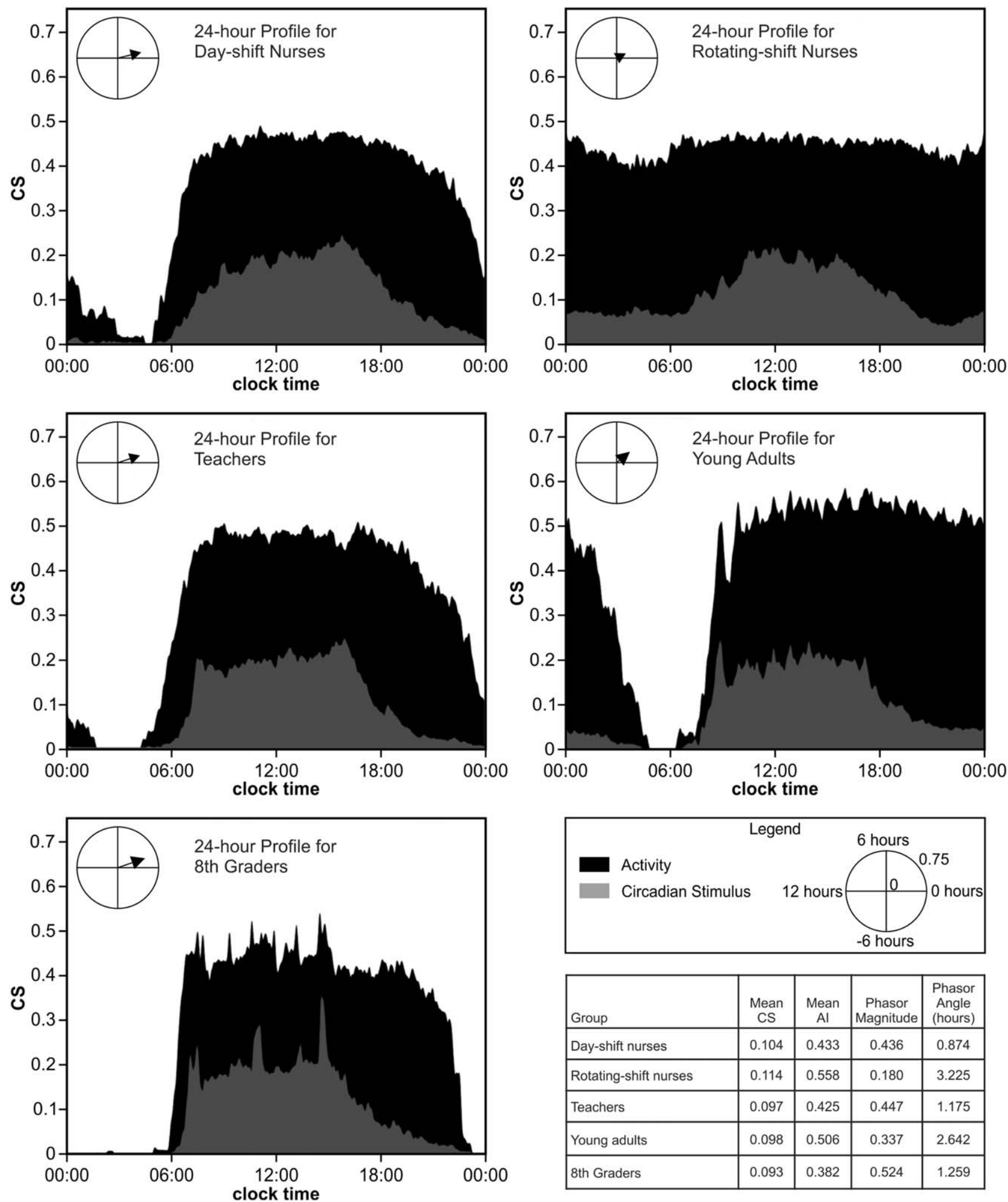

\begin{tabular}{|l|c|c|c|c|}
\hline Group & $\begin{array}{c}\text { Mean } \\
\text { CS }\end{array}$ & $\begin{array}{c}\text { Mean } \\
\text { Al }\end{array}$ & $\begin{array}{c}\text { Phasor } \\
\text { Magnitude }\end{array}$ & $\begin{array}{c}\text { Phasor } \\
\text { Angle } \\
\text { (hours) }\end{array}$ \\
\hline Day-shift nurses & 0.104 & 0.433 & 0.436 & 0.874 \\
\hline Rotating-shift nurses & 0.114 & 0.558 & 0.180 & 3.225 \\
\hline Teachers & 0.097 & 0.425 & 0.447 & 1.175 \\
\hline Young adults & 0.098 & 0.506 & 0.337 & 2.642 \\
\hline 8th Graders & 0.093 & 0.382 & 0.524 & 1.259 \\
\hline
\end{tabular}

Fig. 5. Light and activity patterns for five human populations (day-shift nurses, rotating-shift nurses, teachers, young adults, and eighth graders) as measured with a head-worn Daysimeter-D. Phasor diagrams are included in the upper left corner of each panel showing the magnitude and angle of behavioral circadian entrainment exhibited by each population. Traces represent the daily averages of light and activity over 1 week for each population. It should be noted that the traces for human populations represents averages for more subjects than those shown here for lemurs. For lemurs, the traces represent the average light and activity of four lemurs over a 21-minute duration. For humans, the traces represent the average light and activity for approximately 20 subjects over a 5-minute duration. 
For comparative purposes, Figure 5 shows examples of light and activity patterns, the associated phasors, and the related activity descriptive statistics for five human populations: day-shift nurses, rotating-shift nurses, teachers, young adults, and eighth graders. When compared to Figures 3 and 4, it is clear that lemurs and humans both exhibit largely diurnal behavior, but lemurs respond to their luminous environment slightly differently than modern humans. With the exception of shift workers, humans usually exhibit consolidated sleep during the night and activity during the hours of daylight. Persons with Alzheimer's disease, who tend to exhibit circadian disruption, do not show this behavior. Rather they exhibit random patterns of activity and rest throughout the 24-hour day (Figueiro et al., 2012). Although lemurs also largely exhibited consolidated activity-rest periods with peak activity during the hours of daylight, their behavior is qualitatively different than humans. Humans, at least those studied in North America, do not typically show a burst of activity at or before sunrise and a hiatal period during midday. Moreover, there are differences in activity patterns among the species of lemurs. Among the five species of lemurs studied here, the one that exhibited light exposure and activity patterns that mostly resembled those of humans is the Coquerel's sifaka. As can be seen by comparing Figures 3 and 5, humans are constantly active during the day and experience relatively constant light exposures during the day. Although these patterns are similar to those exhibited by Coquerel's sifaka, there are subtle differences that make each species unique. In general then, it seems that all the lemurs studied exhibit similar, but not identical circadian patterns of light-dark and of activity-rest, and that these patterns, while similar to humans, are still distinct.

Although the Daysimeter-D and its application as a collar-mounted light and activity measurement device for lemurs provided useful data to assess circadian entrainment, the device and methods applied have two limitations that should be addressed in future studies. First, the calibration of the light sensors was based upon the spectral $\left(\mathrm{CL}_{\mathrm{A}}\right)$ and absolute $(\mathrm{CS})$ sensitivities of humans. Depending upon the lemur species, this calibration may or may not be entirely appropriate for drawing inferences about species-specific circadian system responses to light. The absolute threshold for lightinduced activation of the human circadian system is much higher than it is for the human visual system (Rea et al., 2002). This relationship may or may not hold for some or all lemurs. Much is known about the retinal photopigments in lemurs (e.g. Jacobs and Deegan, 1993; Jacobs, 2009), but characterizing their circadian system responses to light, both in terms of spectral and absolute sensitivities, remain an important area of future research. Second, the accelerometers in the collarmounted Daysimeter-D constantly records slight motions, even when the animal is resting. Therefore, it is difficult to segregate nocturnal activity while a lemur is awake from nocturnal motion while the lemur is resting. This too needs to be systematically investigated for accurate assessment of nocturnal activity in lemurs.

Finally, to understand the diurnal, nocturnal, and cathemeral behaviors of different lemur species, it is important that both light and activity be considered. Technologies such as the collar-mounted Daysimeter-D offer a breakthrough in this regard. Data gathered from this device can be used to shed new scientific "light" on the debate about the photic niche of lemurs and ultimately the primate ancestor. Importantly too, such data may also be used to create lighting systems and applications that benefit breeding and long-term husbandry for lemurs held in captivity.

\section{ACKNOWLEDGMENTS}

The authors thank Dr. Erin Ehmke, Andrea Katz, David Brewer and the Duke Lemur Center staff and Martin Overington for their help. They also thank Dennis Guyon at the Lighting Research Center for preparing the graphics. This article benefited from comments by the Editor, Associate Editor, and two anonymous reviewers. This is Duke Lemur Center Publication Number 1253 .

\section{LITERATURE CITED}

Bearder SK, Nekaris KAI, Curtis DJ. 2006. A re-evaluation of the role of vision in the activity and communication of nocturnal primates. Folia Primatol 77:50-71.

Bellingham J, Foster RG. 2002. Opsins and mammalian photoentrainment. Cell Tissue Res 309:57-71.

Bellingham J, Chaurasia SS, Melyan Z, Liu C, Cameron MA, Tarttelin EE, Iuvone PM, Hankins MW, Tosini G, Lucas RJ. 2006. Evolution of melanopsin photoreceptors: discovery and characterization of a new melanopsin in nonmammalian vertebrates. PLoS Biol 4:1334-1343.

Britt, A. 2000. Diet and feeding behaviour of the black-andbhite ruffed lemur (Varecia variegata variegata) in the Betampona Reserve, Eastern Madagascar. Folia Primatol 71: 133-141.

Colquhoun, IC. 2006. Predation and cathemerality. Folia Primatol 77:143-165.

Curtis DJ, Rasmussen MA. 2002. Cathemerality in lemurs. Evol Anthropol 11 (S1):83-86.

Curtis DJ, Rasmussen MA. 2006. The evolution of cathemerality in primates and other mammals: a comparative and chronoecological approach. Folia Primatol 77:178-193.

Curtis DJ, Zaramody A. 1999. Social structure and seasonal variation in the behaviour of Eulemur mongoz. Folia Primatol 70:79-96.

Curtis DJ, Zaramody A Martin RD. 1999. Cathemerality in the mongoose lemur, Eulemur mongoz. Am J Primatol 47:279298.

Donati G, Borgognini-Tarli SM. 2006. Influence of abiotic factors on cathemeral activity: the case of Eulemur fulvus collaris in the littoral forest of Madagascar. Folia Primatol 77: 104-122.

Donati G, Baldi N, Morelli V, Ganzhorn JU, Borgognini-Tarli SM. 2009. Proximate and ultimate determinants of cathemeral activity in brown lemurs. Anim Behav 77:317-325.

Donati G, Bollen A, Borgognini-Tarli SM, Ganzhorn JU. 2007. Feeding over the 24-h cycle: dietary flexibility of cathemeral collared lemurs (Eulemur collaris). Behav Ecol Sociobiol 61: 1237-1251.

Donati G, Lunardini A, Kappeler PM, Borgognini-Tarli SM. 2001. Nocturnal activity in the cathemeral red-fronted lemur (Eulemur fulvus rufus), with observations during a lunar eclipse. Am J Primatol 53:69-78.

Donati G, Ricci E, Baldi N, Morelli V, Borgognini-Tarli SM. 2010. Behavioral thermoregulation in a gregarious lemur, Eulemur collaris: effects of climatic and dietary-related factors. Am J Phys Anthropol 144:355-364.

Donati G, Santini L, Razafindramanana J, Boitani L, Borgognini-Tarli SM. 2013. (Un-) expected nocturnal activity in "diurnal" Lemur catta supports cathemerality as one of the key adaptations of the lemurid radiation. Am J Phys Anthropol 150:99-106.

Erkert HG, Cramer B. 2006. Chronobiological background to cathemerality: circadian rhythms in Eulemur fulvus albifrons 
(Prosimii) and Aotus azarai boliviensis (Anthropoidea). Folia Primatol 77:87-103.

Erkert HG, Kappeler PM. 2004. Arrived in the light: diel and seasonal activity patterns in wild Verreaux's Sifakas (Propithecus v. verreauxi; Primates: Indriidae). Behav Ecol Sociobiol 57:174-186.

Erkert HG, Fernández-Duque E, Rotundo M, Scheideler A. 2012. Seasonal variation of temporal niche in wild owl monkeys (Aotus azarai azarai) of the Argentinean Chaco: a matter of masking? Chronobiol Int 29:702-714.

Fernández-Duque E, Erkert HG. 2006. Cathemerality and lunar periodicity of activity rhythms in owl monkeys of the Argentinian Chaco. Folia Primatol 77:123-138.

Fernández-Duque E, de la Iglesia H, Erkert HG. 2010. Moonstruck primates: owl monkeys (Aotus) need moonlight for nocturnal activity in their natural environment. PLoS ONE 5:1-6.

Figueiro MG, Hamner R, Bierman A, Rea MS. 2012. Comparisons of three practical field devices used to measure personal light exposures and activity levels. Light Res Technol 1-14.

Heesy CP, Ross CF. 2001. Evolution of activity patterns and chromatic vision in primates: morphometrics, genetics and cladistics. J Hum Evol 40:111-149.

Jacobs GH. 2009. Evolution of colour vision in mammals. Philos Trans R Soc Lond B Biol Sci 364:2957-2967.

Jacobs GH, Deegan JF. 1993. Photopigments underlying color vision in ringtail lemurs (Lemur catta) and brown lemurs (Eulemur fulvus). Am J Primatol 30:243-256.

Kappeler PM. 1990. Female dominance in Lemur catta: more than just female feeding priority? Folia Primatol 55:92-95.

Kappeler PM, Erkert HG. 2003. On the move around the clock: correlates and determinants of cathemeral activity in wild redfronted lemurs (Eulemur fulvus rufus). Behav Ecol Sociobiol 54:359-369.

Lafleur M. 2012. Ecology of ring-tailed lemurs (Lemur catta) at the Tsimanampetsotsa National Park, Madagascar: implications for female dominance and the evolution of lemur traits. Dissertation. Boulder, CO: University of Colorado.

Martin RD. 1994. Primate origins and evolution. Princeton,NJ: Princeton Press.

Martin RD, Ross CF. 2005. The evolutionary and ecological context of primate vision. In: Kremers J, Silveira L, Martin P, editors. Structure, function, and evolution of the primate visual system. New York: John Wiley. p 1-36

Martin L, Olejniczak A, Maas C. 2003. Enamel thickness and microstructure in pitheciine primates, with comments on dietary adaptations of the middle Miocene hominoid Kenyapithecus. J Hum Evol 45:351-367.

Miller D, Bierman A, Figueiro MG, Schernhammer E, Rea MS. 2010. Ecological measurements of light exposure, activity, and circadian disruption in real-world environments. Light Res Technol 42:271-284.

Morland H. 1991. Preliminary report on the social organization of ruffed lemurs (Varecia variegata variegata) in a northeast rain forest. Folia Primatol 56:157-161.

Nouvellet P, Rasmussen G, Macdonald D, Courchamp F. 2012. Noisy clocks and silent sunrises: measurement methods of daily activity pattern. J Zool 286:179-184.

Pereira ME, Seeligson M, Macedonia J, Macedonia J. 1988. The behavioral repertoire of the black-and-white ruffed lemur, Varecia variegata variegata (Primates: Lemuridae). Folia Primatol 51:1-32.

Pierson S, Foster RG. 2006. Melanopsin: another way of signaling light. Neuron 49:331-339.

Perry GH, Martin RD, Verrelli BC. 2007. Signatures of functional constraint at aye-aye opsin genes: the potential of adaptive color vision in a nocturnal primate. Mol Biol Evol 24:1963-1970.

Rea MS, Figueiro MG, Bullough JD. 2002. Circadian photobiology: an emerging framework for lighting practice and research. Light Res Technol 34:177-190.
Rea MS, Bierman A, Figueiro MG, Bullough JD. 2008. A new approach to understanding the impact of circadian disruption on human health. J Circadian Rhythms 6:7.

Rea MS, Figueiro MG, Bierman A, Bullough JD. 2010. Circadian Light. J Circadian Rhythms 8:1-11.

Rea MS, Figueiro MG, Bullough JD, Bierman A. 2005. A model of photo-transduction by the human circadian system. Brain Res Rev 50:213-228.

Refinetti R. 2006. Circadian physiology, 2nd ed. Boca Raton,FL: CRC Press.

Richard A 1974. Intra-specific variation in the social organization and ecology of Propithecus verreauxi. Folia Primatol 22: 178-202.

Richard A 1978. Variability in the feeding behavior of a Malagasy prosimian, Propithecus verreauxi, Lemuriformes. In: Montgomery GG, editor. The ecology of arboreal folivores. Washington, DC: Smithsonian Institution Press. p 519-533.

Richard A 1985. Social boundaries in a Malagasy prosimian, the sifaka (Propithecus verreauxi). Int J Primatol 6:553-568.

Ross CF, Kirk EC. 2007. Evolution of eye size and shape in primates. J Hum Evol 52:294-313.

Sauther ML. 1993. Resource competition in wild populations of ringtailed lemurs (Lemur catta): implications for female dominance; In: Kappeler PM, Ganzhorn JU, editors. Lemur social systems and their ecological basis. New York: Plenum Press. p 135-152.

Sauther ML, Sussman RW, Gould L. 1999. The socioecology of the ringtailed lemur: thirty-five years of research. Evol Anthropol 8: 120-132.

Simmen B, Sauther ML, Soma T, Rasamimanana HR, Sussman RW, Jolly A, Tarnaud, L, Hladik A. 2006. Plant species fed on by Lemur catta in gallery forests of the southern domain of Madagascar, In: Jolly A, Sussman RW, Koyama N, Rasamimanana H, editors. Ring-tailed lemur biology. New York: Springer. p 55-68.

Sussman RW. 1974. Ecological distinctions of sympatric species of lemur. In: Martin RD, Doyle GA, Walker AC, editors. Prosimian biology. Pittsburgh: University of Pittsburgh Press. p 75-108.

Sussman R, Tattersall I. 1976. Cycles of activity, group composition, and diet of Lemur mongoz mongoz, Linnaeus 1766 in Madagascar. Folia primatol 26: 270-283.

Tan Y, Yoder AD, Yamashita N, Li WH. 2005. Evidence from opsin genes rejects nocturnality in ancestral primates. PNAS 102:14712-14716.

Tattersall I. 1976. Group structure and activity rhythm in Lemur mongoz (Primates, Lemuriformes) on Anjouan and Mohéli islands, Comoro Archipelago. Anthropol Papers Am Mus Nat Hist 53:363-378.

Tattersall I. 1978. Behavioural variation in Lemur mongoz (= L. m. mongoz). In: Chivers DJ, Joysey KA, editors. Recent advances in primatology: Evolution, Vol. 3. London: Academic Press. p 127-132.

Tattersall I. 1987. Cathemeral activity in primates: a definition. Folia Primatol 49:200-202.

Traina A. 2001. Activity pattern and feeding behaviour of ringtailed lemurs (Lemur catta) at Berenty Reserve in Madagascar during the day and night. Folia Primatol 72:188.

van Schaik CP, Kappeler PM 1996. The social systems of gregarious lemurs: lack of convergence with anthropoids due to evolutionary disequilibrium? Ethology 102:915-941.

Vasey N. 2000. Niche separation in Varecia variegata rubra and Eulemur fulvus albifrons: I. interspecific patterns. Am J Phys Anthropol 112:411-431.

Vasey, N. 2005. Activity budgets and activity rhythms in red ruffed lemurs (Varecia rubra) on the Masoala Peninsula, Madagascar: seasonality and reproductive energetics. Am J Primatol 66:23-44.

White FJ, Burton AS, Buchholz S, Glander KE. 1992. Social organization of free-ranging ruffed lemurs, Varecia variegata variegata: mother-adult daughter relationship. Am J Primatol 28:281-287. 